\title{
Cartilage Tissue Engineering Using Combination of Chitosan Hydrogel and Mesenchymal Stem Cells
}

\author{
Dechao Yuan, ${ }^{1,2}$ Zhu Chen,, Tao Lin, ${ }^{1}$ Xuwei Luo, ${ }^{1}$ Hua Dong, ${ }^{3}$ and Gang Feng ${ }^{1,2}$ \\ ${ }^{1}$ Institute of Tissue Engineering and Stem Cells, Nanchong Central Hospital and the Second Clinical Institute of \\ North Sichuan Medical University, 97 Renmin South Road, Nanchong, Sichuan 637000, China \\ ${ }^{2}$ Sichuan Medical University, 319 3rd Block of Zhongshan Road, Luzhou, Sichuan 646000, China \\ ${ }^{3}$ School of Chemistry, University of Edinburgh, King's Buildings, West Mains Road, Edinburgh EH9 3JF, UK \\ Correspondence should be addressed to Hua Dong; hua.dong@ed.ac.uk and Gang Feng; fenggangncch@163.com
}

Received 2 October 2015; Accepted 26 October 2015

Academic Editor: Jin Geng

Copyright (C) 2015 Dechao Yuan et al. This is an open access article distributed under the Creative Commons Attribution License, which permits unrestricted use, distribution, and reproduction in any medium, provided the original work is properly cited.

A novel chitosan hydrogel with high porosity was fabricated by a crosslinking method. Cartilage tissue engineering formed after mesenchymal stem cells was cultured on this hydrogel scaffold for 12 weeks. The immunohistochemistry tests demonstrated that the obtained cartilage had the specific histological properties of natural cartilage. And the qPCR tests also proved that the genes for type II collagen in the obtained cartilage were expressed the same as in the natural one.

\section{Introduction}

Cartilage impairment is one of the most common diseases in the world. It brings about enormous pains to the patients, brings about considerable economic burden to the society, and brings about a big challenge to the clinicians and researchers [1-3]. Cartilage has little self-healing capability due to its avascular structure. Even if there is new tissue forming at the injured position of cartilage, it usually does not have the biomechanical properties of normal cartilage [4].

Fortunately, the development of tissue engineering in recent years provides a new pathway for cartilage repair [5$7]$. According to the past researches $[8,9]$, tissue engineering normally has three elements, that is, seed cells, scaffolds, and growth factors. Chondrocytes and stem cells are the most used seed cells for cartilage repair at present [10]. However, the source of chondrocytes is very scarce because of the very limited cartilage in body and its poor reproducing capability. Moreover, the extraction process could bring about new impairment to the patients as well [3]. Stem cells are just on the opposite side [11]. Compared with chondrocytes, the stem cells have many advantages, such as abundant source, the easy and little impairing extraction, and flourishing proliferation capability. Moreover, the stem cells can be induced into different kinds of cells, which makes them versatile in the tissue engineering research. Therefore, stem cells become the ideal seed cells for cartilage tissue engineering [12-14].

The second element for cartilage tissue engineering is the scaffold. There are three kinds of scaffold materials; those are natural biomaterials, synthetic polymeric materials, and composited materials. Generally speaking, natural biomaterials have favorable biocompatibility but inferior mechanical stability. In contrast to natural biomaterials, synthetic polymeric materials have favorable mechanical stability but inferior biocompatibility [15]. Composited materials are normally composited with natural biomaterials with some synthetic parts. They can provide the scaffold with favorable biocompatibility as well as strong stability. Although the more complicated fabrication process could be their disadvantage, composited materials provide the researchers with a better choice on the scaffold materials. The scaffold for cartilage tissue engineering should have good biocompatibility and considerable porosity [16]. It should be favorable for cell growth and differentiation as well [17]. The scaffold used in this research was chitosan hydrogel. Hydrogels are normally made to a three-dimensional construct in which cells can anchor, grow, differentiate, and excrete extracellular matrix. Due to their mechanical properties similar to natural tissue, 
hydrogels are broadly used as the scaffold for tissue engineering. Chitosan has similar properties with glycosaminoglycans, which are the main composition of extracellular matrix in cartilage tissue $[18,19]$. The nonimmunogenic property of chitosan hydrogel is a special advantage for implantation in vivo as well as for tissue culture in vitro. With special fabrication process, we can also endow it with highly porous structure.

Growth factor, which is another element, is very important if the stem cells are supposed to be differentiated into some special cells [20]. It is the signal to induce stem cells to differentiate. At present, the usually used cartilage inducing growth factors include TGF- $\beta$, BMP, and IGF-1 [21-23]. TGF$\beta$ series are composed of TGF- $\beta 1$, TGF- $\beta 2$, TGF- $\beta 3$, and TGF- $\beta 4$. They can promote the differentiation of cartilage by improving the expression of cartilage transcription factor SOX9 [24]. TGF- $\beta 1$, which can stimulate the secretion of Aggrecan and type II collagen and keep the phenotype of chondrocyte stable, is the major cell factor to induce MSCs to differentiate into chondrocytes [23]. In this research, we used TGF- $\beta 1$ as the growth factor, modified chitosan as the scaffold material, and considered MSCs as the seed cells to explore a novel cartilage regeneration method. The obtained cartilage tissue was proved the same as its natural counterpart by immunohistochemistry staining tests and qPCR tests.

\section{Materials and Methods}

2.1. Materials and Instruments. The materials and instruments used include Mesenchymal stem cells (extracted from 2-week-old New Zealand white rabbits), $\mathrm{CO}_{2}$ incubator (Thermo), Safranin-O staining solution (Sigma), type II collagenase (Sigma), inverted phase contrast microscope (Nikon), Aggrecan primary and secondary antibodies (Thermo), iQ5 RT-PCR (Bio-Rad), scanning electronic microscopy (JSM-7500F, JEOL), FBS (HyClone), NEAA, 2ME, vitamin C, TGF- $\beta 1$, ITS-Premix, and L-proline (Sigma).

2.2. The Fabrication of Chitosan Hydrogel. $0.8 \mathrm{~mL}$ 1,6-diisocyanatohexane was mixed thoroughly with $1.0 \mathrm{~mL}$ polyethylene glycol (PEG) 200, and then the mixture was stirred at $25^{\circ} \mathrm{C}$ for 3 days to synthesize the crosslinker. $10 \mu \mathrm{L}$ of the obtained crosslinker was added into $1 \mathrm{~mL}$ chitosan solution $(1 \% \mathrm{w} / \mathrm{w})$ and then mixed thoroughly. The chitosan scaffold was obtained after the lyophilization of the mixture.

2.3. Stem Cells Culturing and Cartilage Inducement. Primary mesenchymal cells from rabbits were passaged twice. The obtained second passage (P2) cells were diluted to $2 \times$ $10^{7} \mathrm{~mL}^{-1}$ to be ready for use.

The inducing culturing of stem cells was carried out in a cartilage inducing medium, which contained 10\% FBS, $10 \mathrm{mM}$ nonessential amino acids, $55 \mu \mathrm{M} 2-\mathrm{ME}, 50 \mu \mathrm{g} / \mathrm{mL}$ vitamin C, $10 \mathrm{ng} / \mathrm{mL}$ TGF- $\beta 1,1 \%$ ITS-Premix, $40 \mu \mathrm{g} / \mathrm{mL}$ L-proline, $100 \mathrm{mM}$ hexadecadrol, and $1 \%$ penicillin/streptomycin.
The scaffold material was cut into $2 \times 3 \times 5 \mathrm{~mm}$ cubic shape and was sterilized in a well plate. $0.1 \mathrm{~mL} 2 \times 10^{7} \mathrm{~mL}^{-1}$ P2 cell suspension was added into the scaffold material. $2 \mathrm{~mL}$ inducing culturing medium was then added into the well after 4 hours. Then the well plate was kept at $37^{\circ} \mathrm{C}, 5 \% \mathrm{CO}_{2}$, saturated humidity to be cultured for 12 weeks. The inducing culturing medium was changed every two days. The well plate was changed every week.

2.4. Scanning Electronic Microscopy (SEM). SEM investigation was carried out on JEOL JSM-7500 SEM machine. The samples were coated with gold to increase their conductivity before the observation.

2.5. Immunohistochemistry Staining. The paraffin-embedded sections of the obtained tissue were carried out to test its biochemical composition. The hematein-eosin staining and Safranin O-fast green staining were performed with the traditional methods. To realize type II collagen immunohistochemistry staining, the tissue was treated with $10 \mathrm{mM}$ pH 6 sodium citrate for $3 \mathrm{~min}, 2 \%$ hyaluronidase for $30 \mathrm{~min}$, $3 \% \mathrm{H}_{2} \mathrm{O}_{2}$ for $10 \mathrm{~min}, 0.3 \%$ Triton-100 incubating for $10 \mathrm{~min}$, and BSA antigen blocking for $30 \mathrm{~min}$. Then the tissue was incubated with type II collagen primary antibody overnight at $4^{\circ} \mathrm{C}$ and then incubated with type II collagen secondary antibody for 1 hour at room temperature. Then after being visualized with $3,3^{\prime}$-diaminobenzidine for 5-10 min, the sample was blocked with neutral resin. To realize Aggrecan immunofluorescence imaging, the tissue was treated with $10 \mathrm{mM}$ pH 6 sodium citrate for $3 \mathrm{~min}, 0.3 \%$ Triton100 incubating for $10 \mathrm{~min}$, and BSA antigen blocking for $30 \mathrm{~min}$. And then the tissue was incubated with Aggrecan primary antibody overnight at $4^{\circ} \mathrm{C}$ and incubated with Aggrecan secondary antibody for 1 hour at room temperature. The sample was blocked with antifluorescence quenching reagent.

2.6. PCR Tests. Natural and fabricated cartilage tissues were extracted to carry out PCR tests. Total RNA was isolated using the SV Total RNA Isolation System, following the manufacturer's instructions. RNA quantification and quality were determined using the 260/280 nm ratio. Each RNA sample was then reverse-transcribed to cDNA using TaqMan Reverse Transcription Reagents in a thermocycler set at $42^{\circ} \mathrm{C}$ for $60 \mathrm{~min}$ and at $95^{\circ} \mathrm{C}$ for $5 \mathrm{~min}$. The primer sequences used in this study were the following:

Type II collagen: F: 5-GCAGCACGTGTGGTTTGG3; R: 5-CAGGCTGCTGTCTCCATAGCT-3.

Aggrecan: F: 5-GACTTCCCTCCAGTGAGCTG-3; R: 5-CCAGGTCAGGGATTCTGTGT-3.

GAPDH: F: 5-GAGCTGAACGGGAAACTCAC-3; R: 5-CCCTGTTGCTGTAGCCAAAT-3.

Real-time PCR was performed using SYBR Green Master Mix. cDNA $(2 \mu \mathrm{L})$ was added to bring the final volume of the real-time PCR sample to $25 \mu \mathrm{L}$. Then the samples were run for 35 to 45 times amplification. 


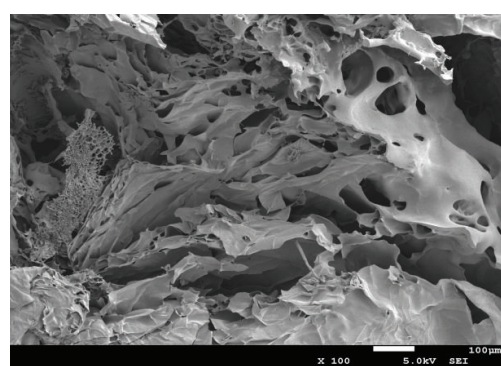

(a)

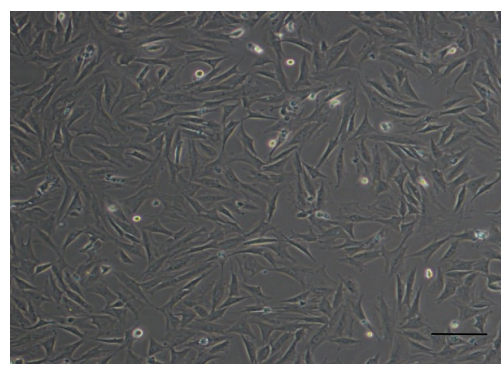

(c)

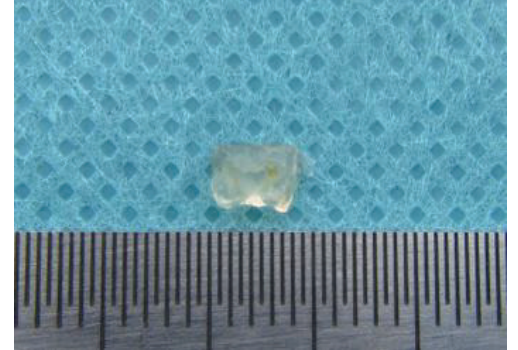

(b)

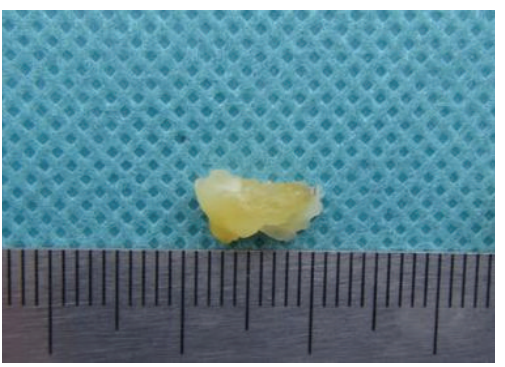

(d)

Figure 1: (a) SEM image of the chitosan scaffold; scale bar: $100 \mu \mathrm{m}$. (b) Optical image of the water saturated chitosan scaffold. (c) Optical image of the mesenchymal stem cells used in cartilage reconstruction; scale bar: $100 \mu \mathrm{m}$. (d) Optical image of the tissue obtained after culturing for 12 weeks.

\section{Results and Discussion}

3.1. Morphology of the Chitosan Scaffold. Generally, an ideal scaffold for tissue engineering should have some properties. (1) It should have excellent biocompatibility, low immunogenicity, and suitable decomposition speed. These properties could ensure the compatibility of the scaffold with the body and keep the speed of tissue growth matching with the speed of scaffold decomposition. (2) It should have favorable porosity. Porosity is the guarantee for cell expansion and substance exchange in the scaffold. (3) It should also have surface favorable for cells to adhere, to proliferate, and to differentiate. (4) Finally it should have suitable mechanical properties which match the properties of the related parts in body. In this research, chitosan was chosen as the base of the scaffold. Considering the fact that the mechanical stability of chitosan is not good enough, we employed crosslinking to reinforce its inner structure. As shown in Figure 1(a), crosslinking-lyophilization process provided the scaffold with very good porous structure. This kind of structure is very helpful for seed cells to enter the scaffold and can also promote the exchange of nutrients and metabolites.

When the chitosan scaffold was saturated with water, it became a gel like morphology in a short time (Figure 1(b)). The high water adsorption capacity can accelerate the access of seed cells to the scaffold at the beginning of cell culturing.

\subsection{Cartilage Induction Culturing. MSCs $\mathrm{P} 2$ cells from rabbit} showed spindle, long triangle, or polygon morphologies (Figure 1(c)). These are the typical morphologies of MSCs. It means that the cells had very good viability. As described in experimental section, growth factor TGF- $\beta 1$ was added into the culturing solution to induce the differentiation of stem cells into chondrocytes. After culturing for 12 weeks, a cartilage like tissue was obtained (Figure 1(d)). The obtained tissue has a half transparent, elastic, and gel like structure.

3.3. Immunohistochemistry Tests. Immunohistochemistry tests were carried out to make sure that the histological compositions of the fabricated cartilage were the same as natural cartilage. Figures 2(a) and 2(b) show the hemateineosin staining results. Cells in the tissue grew boomingly. Extracellular matrix (ECM) was synthesized in large scale and cartilage hollow formed successfully. The arrow in Figure 2(a) indicates the scaffold material in the tissue. Figures 2(c) and 2(d) show the Safranin O-fast green staining results. The ECM was reddish orange, and the nuclei were dark red. The scaffold materials showed light red color. The cartilage hollow, which could not be colored, was also obvious in the images. Figures 2(e) and 2(f) show that the type II collagen immunohistochemistry staining results were positive. The ECM and the area inside the scaffold were sepia in the image. Cellular nuclei were light blue, and the scaffold material (arrow) and cartilage hollow were negative. Figures 2(g) and 2(h) showed Aggrecan immunofluorescence images of the fabricated cartilage tissue. Both of the cells and scaffold had green fluorescence. It means that Aggrecan had been secreted into the scaffold to form cartilage ECM. The results from immunohistochemistry staining prove that the biochemical compositions of the fabricated cartilage tissue were the same as the natural ones. 


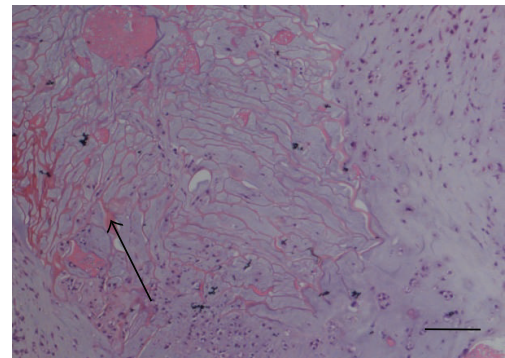

(a)

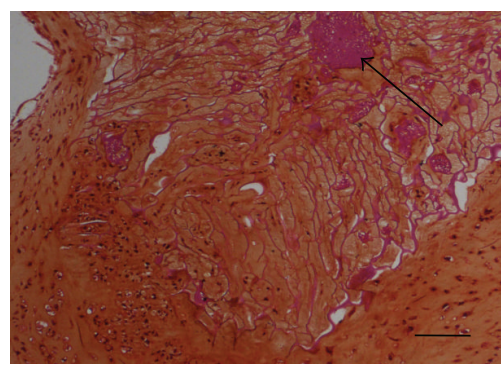

(c)

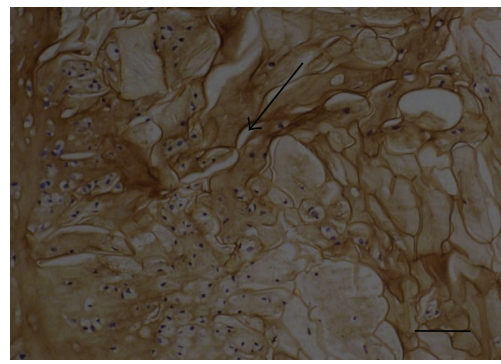

(e)

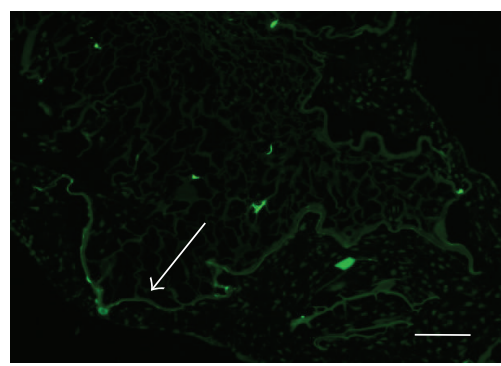

(g)

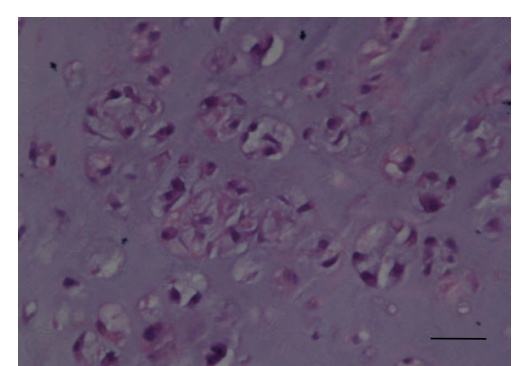

(b)

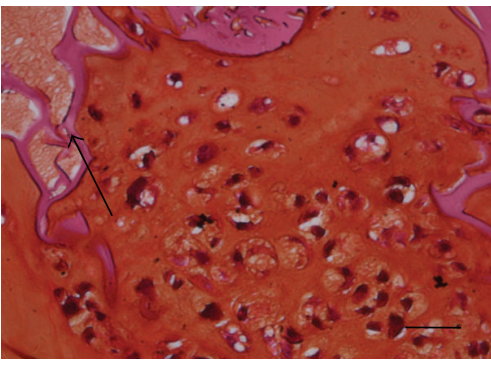

(d)

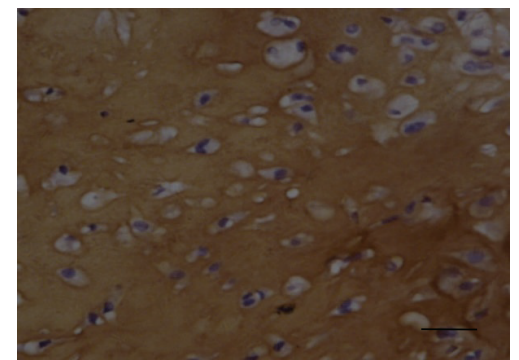

(f)

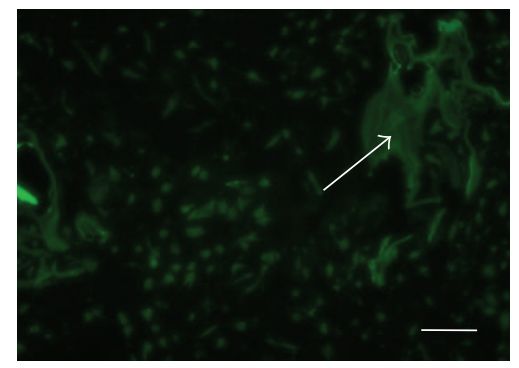

(h)

FIGURE 2: The immunohistochemistry staining results of the fabricated cartilage tissue. (a) and (b) Hematein-eosin staining. (c) and (d) Safranin O-fast green staining. (e) and (f) Type II collagen immunohistochemistry staining. (g) and (h) Aggrecan immunofluorescence imaging. Arrows in the images indicate scaffold material in the tissue. The immunohistochemistry staining results prove that the fabricated tissue has the same biochemical composition as natural cartilage tissue. Scale bar: (a), (c), (e), and (g): $100 \mu \mathrm{m}$; (b), (d), (f), and (h): $25 \mu \mathrm{m}$.

3.4. RT-PCR. As shown in Figure 3, the expression of type II collagen gene in the fabricated cartilage tissue had no statistical significance. It means that type II collagen in the tissue was everywhere. The expression of type II collagen had reached the level of natural cartilage tissue.

\section{Conclusions}

Using a crosslinking method, we fabricated a novel chitosan scaffold material. SEM images showed that the scaffold had excellent porous structure. After inducing culturing of MSCs on this scaffold for 12 weeks, an artificial cartilage tissue was obtained. The immunohistochemistry results prove that the obtained tissue had the same biochemical compositions as the natural cartilage tissue and that the typical cartilage structure formed in the obtained tissue as well. The expression of type II collagen gene of the obtained cartilage tissue also reached the level of its natural counterpart. The fabrication of this novel artificial cartilage tissue is easy, cheap, and fast. It could provide a favorable choice for future clinical application. 


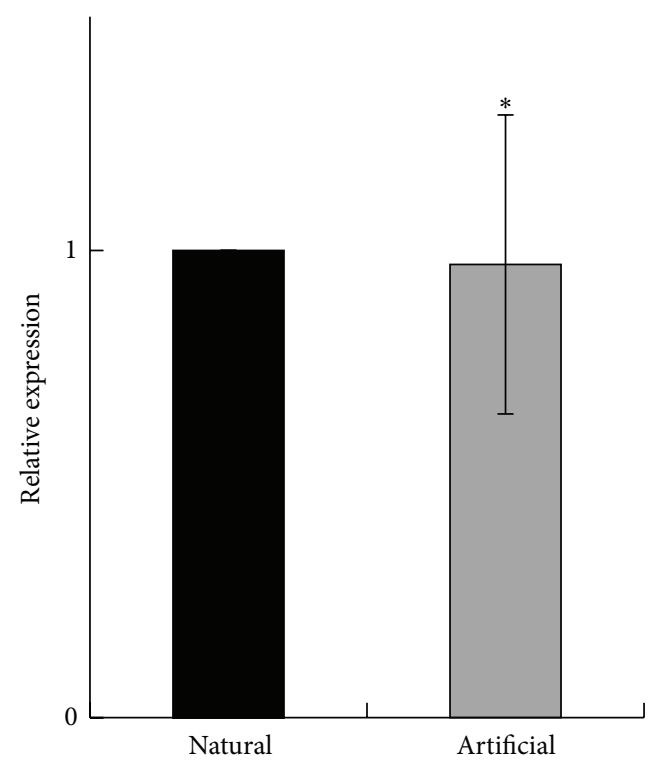

Figure 3: Gene expression of type II collagen in cartilage tissue. Black column: type II collagen expression in natural cartilage tissue as the control. Grey column: type II collagen expression in the fabricated cartilage tissue.

\section{Conflict of Interests}

The authors declare that there is no conflict of interests regarding the publication of this paper.

\section{Acknowledgments}

This work was supported by the Natural Science Foundation of China (81171472 and 81201407), Innovation Team Project Of Sichuan Provincial Education Department (13TD0030), and Major Transformation Cultivation Project of Sichuan Provincial Education Department (15CZ0021).

\section{References}

[1] N. A. Mall, J. D. Harris, and B. J. Cole, "Clinical evaluation and preoperative planning of articular cartilage lesions of the knee," Journal of the American Academy of Orthopaedic Surgeons, vol. 23, no. 10, pp. 633-640, 2015.

[2] F. McCormick, J. D. Harris, G. D. Abrams et al., "Trends in the surgical treatment of articular cartilage lesions in the United States: an analysis of a large private-payer database over a period of 8 years," Arthroscopy, vol. 30, no. 2, pp. 222-226, 2014.

[3] C. P. Hannon, N. A. Smyth, C. D. Murawski et al., "Osteochondral lesions of the talus: aspects of current management," Bone and Joint Journal, vol. 96, no. 2, pp. 164-171, 2014.

[4] H. Madry and M. Cucchiarini, “Tissue-engineering strategies to repair joint tissue in osteoarthritis: nonviral gene-transfer approaches," Current Rheumatology Reports, vol. 16, article 450, 2014.

[5] E. B. Hunziker, K. Lippuner, M. J. B. Keel, and N. Shintani, "An educational review of cartilage repair: precepts \& practicemyths \& misconceptions-progress \& prospects," Osteoarthritis and Cartilage, vol. 23, no. 3, pp. 334-350, 2015.
[6] R. Mardones, C. M. Jofré, and J. J. Minguell, "Cell therapy and tissue engineering approaches for cartilage repair and/or regeneration," International Journal of Stem Cells, vol. 8, no. 1, pp. 48-53, 2015.

[7] K. L. Caldwell and J. Wang, "Cell-based articular cartilage repair: the link between development and regeneration," Osteoarthritis and Cartilage, vol. 23, no. 3, pp. 351-362, 2015.

[8] T. B. F. Woodfield, J. M. Bezemer, J. S. Pieper, C. A. van Blitterswijk, and J. Riesle, "Scaffolds for tissue engineering of cartilage," Critical Reviews in Eukaryotic Gene Expression, vol. 12, no. 3, pp. 209-236, 2002.

[9] M. Nomi, H. Miyake, Y. Sugita, M. Fujisawa, and S. Soker, "Role of growth factors and endothelial cells in therapeutic angiogenesis and tissue engineering," Current Stem Cell Research \& Therapy, vol. 1, no. 3, pp. 333-343, 2006.

[10] M. Mazor, E. Lespessailles, R. Coursier, R. Daniellou, T. M. Best, and $\mathrm{H}$. Toumi, "Mesenchymal stem-cell potential in cartilage repair: an update," Journal of Cellular and Molecular Medicine, vol. 18, no. 12, pp. 2340-2350, 2015.

[11] S. M. Richardson, G. Kalamegam, P. N. Pushparaj et al., "Mesenchymal stem cells in regenerative medicine: focus on articular cartilage and intervertebral disc regeneration," Methods, 2015.

[12] S. Grässel and J. Lorenz, "Tissue-engineering strategies to repair chondral and osteochondral tissue in osteoarthritis: use of mesenchymal stem cells," Current Rheumatology Reports, vol. 16, article 450, 2014.

[13] T. D. Bornes, A. B. Adesida, and N. M. Jomha, "Mesenchymal stem cells in the treatment of traumatic articular cartilage defects: a comprehensive review," Arthritis Research and Therapy, vol. 16, article 432, 2014.

[14] V. Savkovic, H. Li, J. K. Seon, M. Hacker, S. Franz, and J. C. Simon, "Mesenchymal stem cells in cartilage regeneration," Current Stem Cell Research \& Therapy, vol. 9, no. 6, pp. 469488, 2014.

[15] P. B. Lin, L. J. Ning, Q. Z. Lian et al., "A study on repair of porcine articular cartilage defects with tissue-engineered cartilage constructed in vivo by composite scaffold materials," Annals of Plastic Surgery, vol. 65, no. 4, pp. 430-436, 2010.

[16] J. B. Jonnalagadda, I. V. Rivero, and J. S. Dertien, "In vitro chondrocyte behavior on porous biodegradable poly ( $\varepsilon$-caprolactone)/polyglycolic acid scaffolds for articular chondrocyte adhesion and proliferation," Journal of Biomaterials Science Polymer, vol. 26, pp. 401-419, 2015.

[17] D. J. Huey, J. C. Hu, and K. A. Athanasiou, "Unlike bone, cartilage regeneration remains elusive," Science, vol. 338, no. 6109, pp. 917-921, 2012.

[18] T. Jiang, M. Deng, R. James, L. S. Nair, and C. T. Laurencin, "Micro- and nanofabrication of chitosan structures for regenerative engineering," Acta Biomaterialia, vol. 10, no. 4, pp. 1632$1645,2014$.

[19] R. Abdeen and N. Salahuddin, "Modified chitosan-clay nanocomposite as a drug delivery system intercalation and in vitro release of ibuprofen," Journal of Chemistry, vol. 2013, Article ID 576370, 9 pages, 2013.

[20] G. Feng, Y. Wan, G. Balian, C. T. Laurencin, and X. Li, "Adenovirus-mediated expression of growth and differentiation factor-5 promotes chondrogenesis of adipose stem cells," Growth Factors, vol. 26, no. 3, pp. 132-142, 2008.

[21] J. Lam, S. Lu, F. K. Kasper, and A. G. Mikos, "Strategies for controlled delivery of biologics for cartilage repair," Advanced Drug Delivery Reviews, vol. 84, pp. 123-134, 2015. 
[22] M. Griffin, S. Hindocha, and W. S. Khan, "Chondrogenic differentiation of adult MSCs," Current Stem Cell Research and Therapy, vol. 7, no. 4, pp. 260-265, 2012.

[23] A.-M. Freyria and F. Mallein-Gerin, "Chondrocytes or adult stem cells for cartilage repair: the indisputable role of growth factors," Injury, vol. 43, no. 3, pp. 259-265, 2012.

[24] H. Betre, S. R. Ong, F. Guilak, A. Chilkoti, B. Fermor, and L. A. Setton, "Chondrocytic differentiation of human adiposederived adult stem cells in elastin-like polypeptide," Biomaterials, vol. 27, no. 1, pp. 91-99, 2006. 

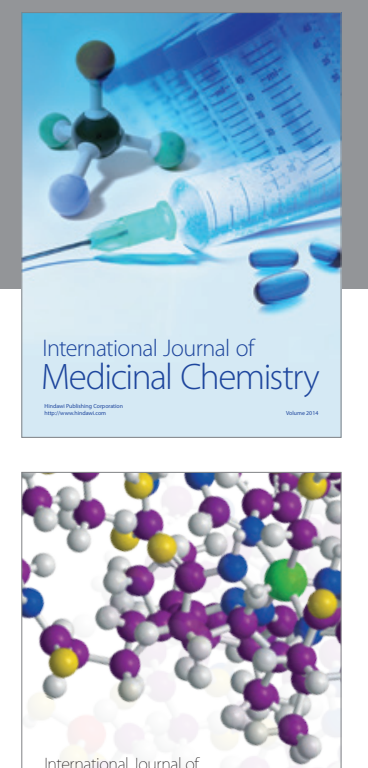

\section{Carbohydrate} Chemistry

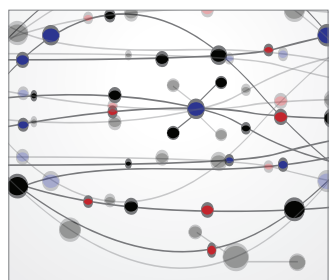

The Scientific World Journal
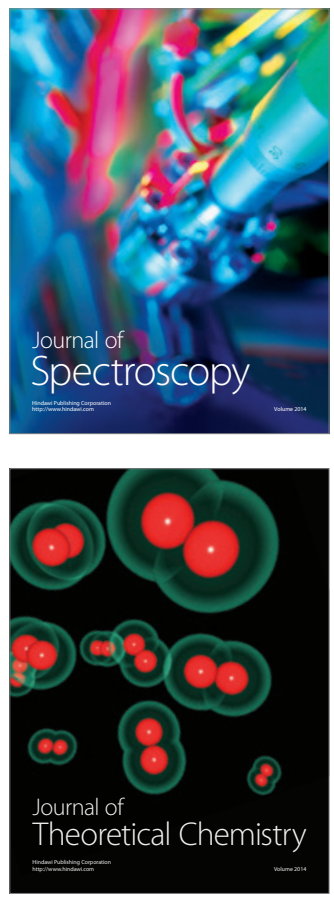
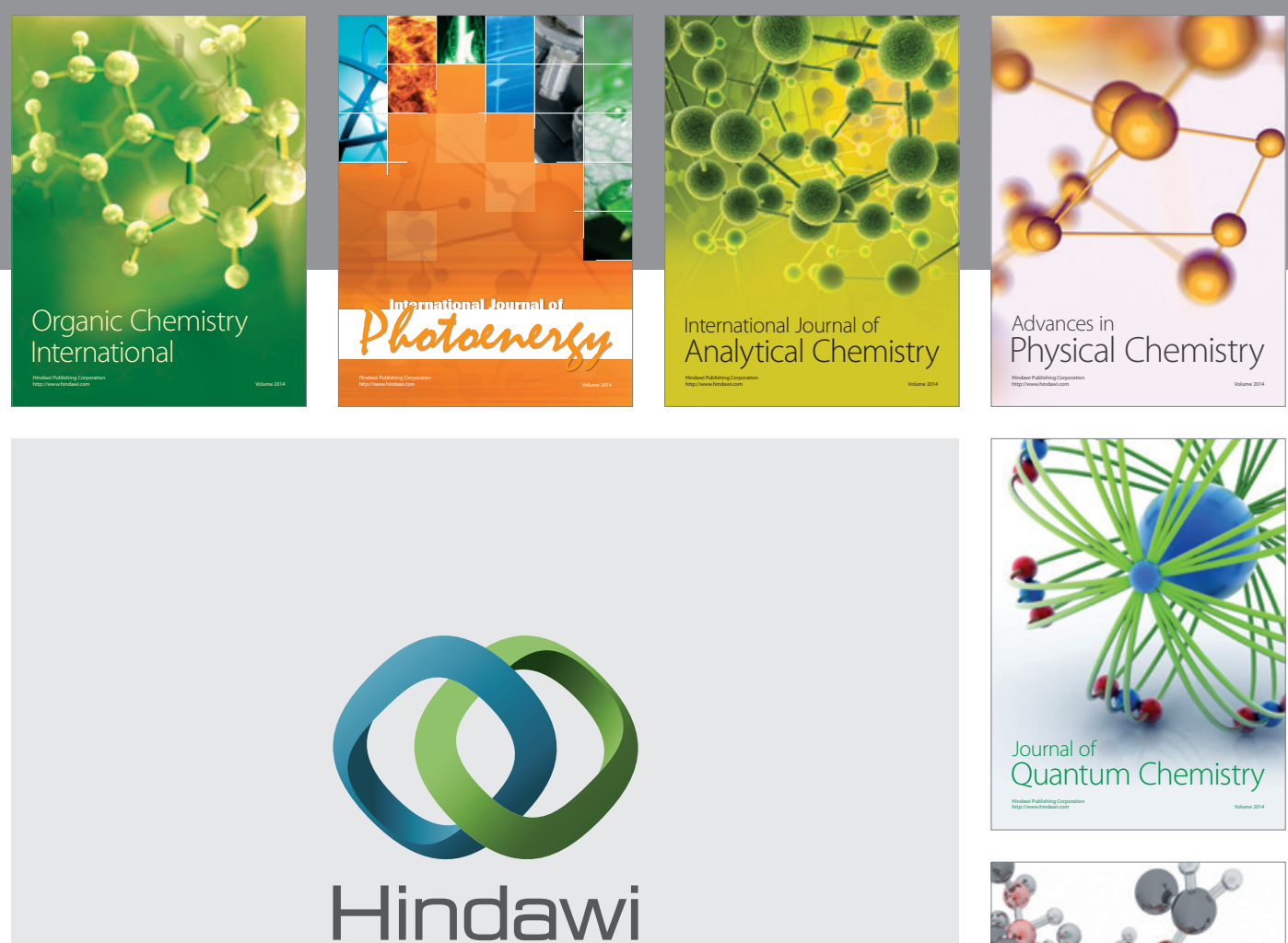

Submit your manuscripts at

http://www.hindawi.com

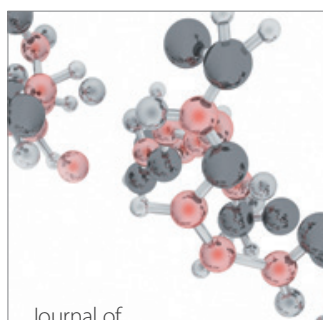

Analytical Methods

in Chemistry

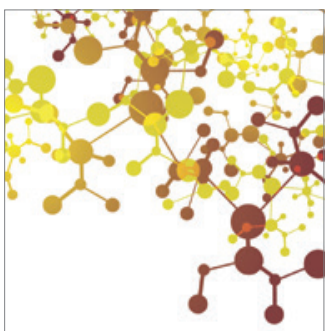

Journal of

Applied Chemistry

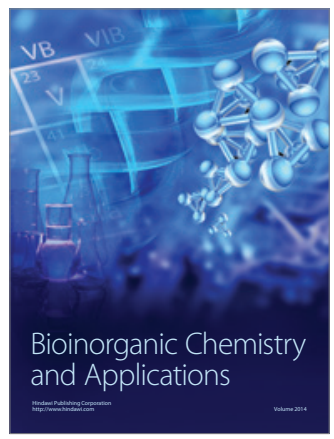

Inorganic Chemistry
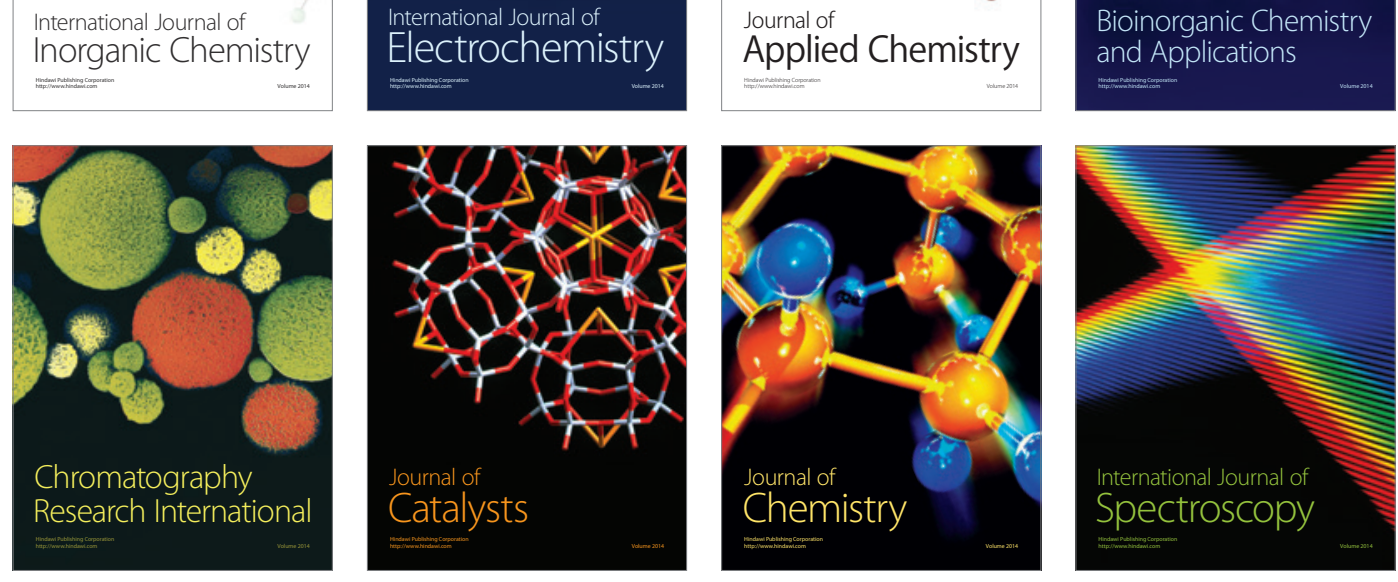